\title{
GUIDELINES
}

\section{Chapter 13. Diagnosis of CKD in the elderly}

(C) Japanese Society of Nephrology 2009

- In the elderly, age-associated kidney dysfunction in addition to primary/secondary kidney diseases leads to the frequent occurrence of CKD stages 3-5.

- It is important to recognize urinary tract malignancy in the elderly with hematuria.

\section{Notable points in elderly CKD patients}

- In the elderly, kidney function (GFR) declines with age. In patients with GFR less than $50 \mathrm{~mL} / \mathrm{min} / 1.73 \mathrm{~m}^{2}$, the decline rate of GFR is at least twice as fast as that in patients with GFR 60-70 mL/min/1.73 $\mathrm{m}^{2}$ (Fig. 13-1).
- Blood pressure control and modification of diet are important for the diagnosis and management of primary disease.

- Physicians attempt to detect ischemic heart disease in cooperation with cardiologists.

- In cases of severe atherosclerosis, blood pressure is gradually lowered, because these patients often develop orthostatic hypotension or transient cerebral ischemic attack.

- Volume depletion or volume expansion is carefully controlled to avoid exacerbation of kidney function.

- Kidney function tends to be worsened by various drugs, such as anti-bacterial drugs, analgesic drugs like NSAIDs, calcium-containing agents, and active vitamin D.
Fig. 13-1 Simulation of ageassociated decline of kidney function. Data are quoted from: Epidemiology Working Group, CKD Management Committee, the Japanese Society of Nephrology 2006
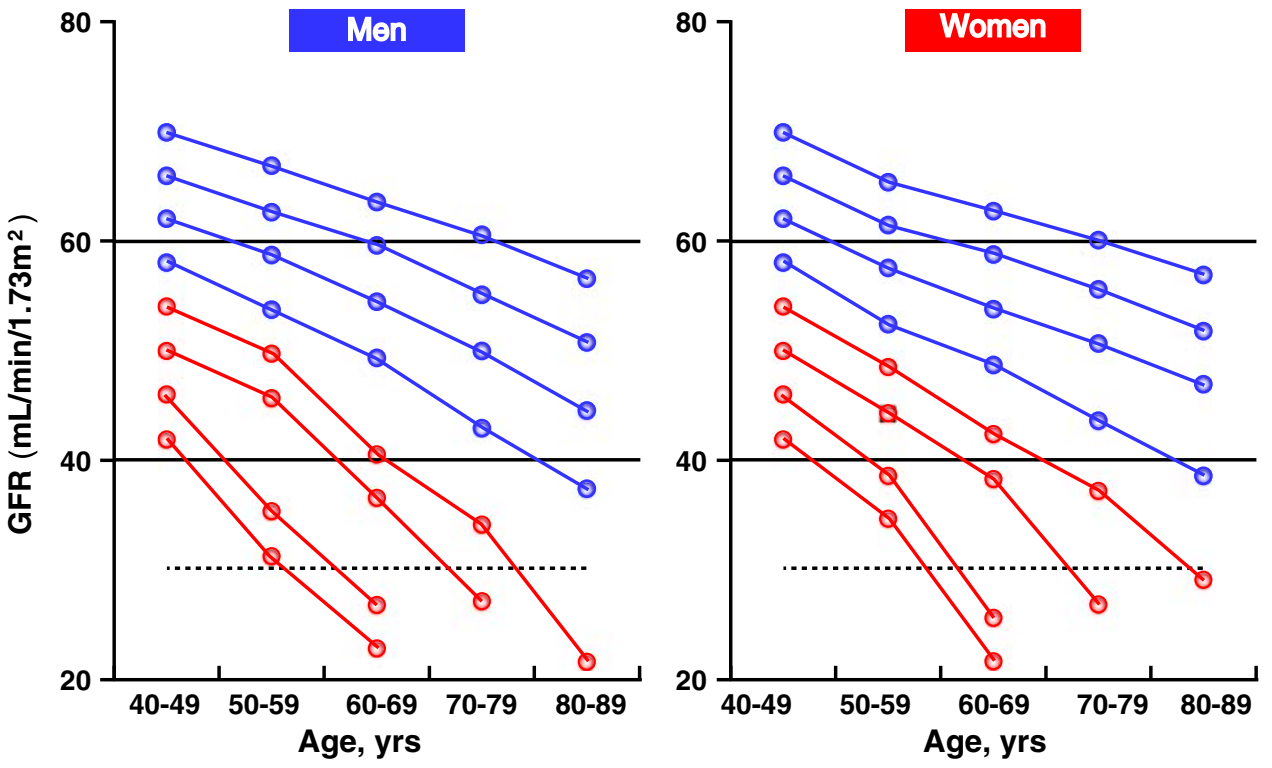

Those whose eGFR is less than $50 \mathrm{~mL} / \mathrm{min} / 1.73 \mathrm{~m}^{2}$ (if age $<69 \mathrm{yrs}$ ) or less than $40 \mathrm{~mL} / \mathrm{min} / 1.73 \mathrm{~m}^{2}$ (if age 70-79yrs) may need dialysis in 10 years. 
Table 13-1 Kidney disease in the elderly

\begin{tabular}{|c|c|c|c|}
\hline & Primary & Secondary & Hereditary/congenital \\
\hline Glomerular disease & $\begin{array}{l}\text { Membranous nephropathy } \\
\text { Minimal change nephrotic } \\
\text { syndrome } \\
\text { Focal segmental } \\
\text { glomerulosclerosis } \\
\text { IgA nephropathy }\end{array}$ & $\begin{array}{l}\text { Hypertensive nephropathy } \\
\text { (nephrosclerosis) } \\
\text { Diabetic nephropathy } \\
\text { Microscopic PN (ANCA-associated } \\
\quad \text { vasculitis) } \\
\text { Renal amyloidosis } \\
\text { Hepatitis C-associated nephropathy }\end{array}$ & \\
\hline $\begin{array}{l}\text { Tubulo-interstitial and urinary } \\
\text { tract disease }\end{array}$ & Chronic interstitial nephritis & $\begin{array}{l}\text { Myeloma kidney } \\
\text { Gouty kidney } \\
\text { Ischemic nephropathy } \\
\text { Drug-induced nephropathy }\end{array}$ & $\begin{array}{l}\text { Prostate hypertrophy (post-renal } \\
\text { renal failure) } \\
\text { Polycystic kidney disease } \\
\text { Urinary stone } \\
\text { Malignancies in the urinary tract }\end{array}$ \\
\hline
\end{tabular}

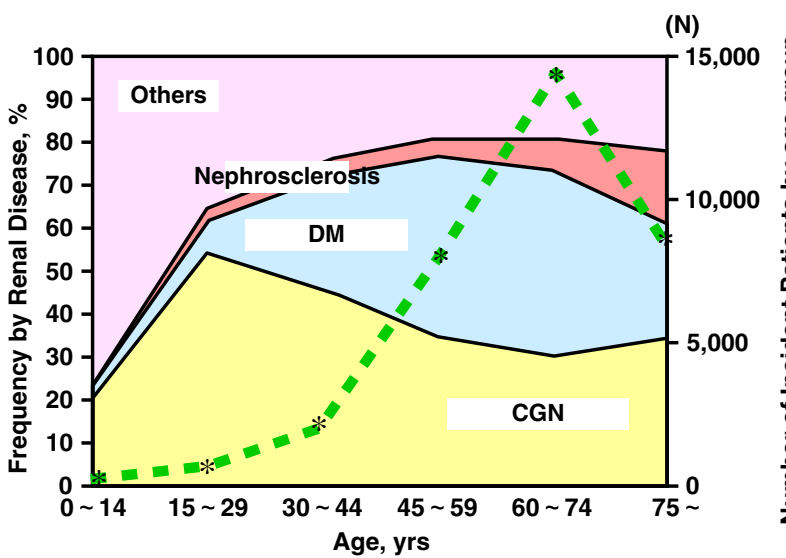

Fig. 13-2 The prevalence of primary diseases responsible for chronic dialysis therapy by age group. Quoted, with modification, from: The Current Status of Chronic Dialysis Therapy in Our Country (as of December 31, 2006) edited by The Japanese Society for Dialysis Therapy

- In some elderly CKD patients aged 70 years or older, CKD control can be awaited until the eGFR is $40 \mathrm{~mL} /$ $\min / 1.73 \mathrm{~m}^{2}$.

\section{Kidney diseases prevalent in the elderly (Table 13-1)}

- The number of elderly dialysis patients has increased remarkably: the mean age of dialysis induction in 2007 was 66.4 years. Of 36,909 patients, $59.9 \%$ were elderly, aged 65 years or older. Among the major causes of ESKD, chronic glomerulonephritis is decreasing, while nephrosclerosis and diabetic nephropathy are increasing (Fig. 13-2).

- The incidence of renal and urinary tract malignancy increases with aging, so physicians need to pay more attention.

- In a case of malignancy, the main urinary finding is hematuria. Ultrasonography, DIP and urine cytology are of diagnostic value. Consultation with urologists is recommended.

- Among kidney diseases in the elderly, nephrosclerosis, gouty kidney, drug-induced kidney dysfunction, and urological disease often do not show significant urinary abnormalities. Hence, evaluation of eGFR is essential for the diagnosis of CKD.

- In myeloma kidney or renal amyloidosis in the elderly, urinary protein may be negative with the dipstick test, but positive with a quantitative method.

- Acute decline in kidney function in the elderly is seen in rapidly progressive glomerulonephritis and acute interstitial nephritis. In these cases, frequent measurement of serum creatinine is necessary because serum creatinine increases rapidly over several weeks to months, leading to kidney failure.

- Postrenal kidney failure is often seen due to prostatic hypertrophy or urinary tract obstruction. 